\title{
Midterm Results Following Minimally Invasive Distal Chevron Osteotomy: Comparison With the Minimally Invasive Reverdin-Isham Osteotomy by Means of Meta-analysis
}

\author{
GERHARD KAUFMANN ${ }^{1}$, DANIEL WEISKOPF ${ }^{2}$, MICHAEL LIEBENSTEINER ${ }^{2}$, HANNO ULMER $^{3}$, \\ MATTHIAS BRAITO ${ }^{4}$, FRANZ ENDSTRASSER ${ }^{4}$, MORITZ WAGNER ${ }^{4}$, \\ MICHAEL BAN ${ }^{2}$ and DIETMAR DAMMERER ${ }^{2}$

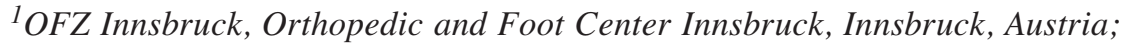 \\ ${ }^{2}$ Department of Orthopaedics and Traumatology, Medical University of Innsbruck, Innsbruck, Austria; \\ ${ }^{3}$ Department of Medical Statistics, Informatics and Health Economics, \\ Medical University of Innsbruck, Innsbruck, Austria; \\ ${ }^{4}$ Department of Orthopaedics and Traumatology, St. Johann in Tirol, Austria
}

\begin{abstract}
Background/Aim: To date, multiple different surgical techniques have been established for hallux valgus surgery, with each technique having its unique advantages and limitations. The open distal chevron osteotomy is widely accepted, but increasing patient demands have led several minimally invasive (MIS) techniques to be described in recent years. The aim of this study was to compare outcomes after minimally invasive (MIS) distal chevron osteotomy and the minimally invasive Reverdin-Isham method. Patients and Methods: We assessed clinical and radiographic outcomes after MIS chevron osteotomy in 57 feet of 49 consecutive patients with a mean follow-up of 58.9 (range=39.0-85.4) months. Outcomes after MIS Reverdin-Isham osteotomy were analyzed by means of a systematic literature review with a minimum follow-up of 6 months. Results: Radiographic outcomes were significantly better in the MIS chevron cohort for intermetatarsal angle $(p<0.001)$, hallux valgus angle and distal metacarpal articular angle $(p<0.05)$. Concerning clinical outcomes, both methods provided comparable improvement. Conclusion: MIS distal chevron osteotomy in mild to moderate hallux valgus deformity correction results
\end{abstract}

This article is freely accessible online.

Correspondence to: Dietmar Dammerer, MD, Ph.D., PD, Department of Orthopaedics and Traumatology, Medical University of Innsbruck, Anichstrasse 35, 6020 Innsbruck, Austria. Tel: +43 51250422692, e-mail: dietmar.dammerer@tirol-kliniken.at

Key Words: Chevron, Reverdin-Isham osteotomy, Hallux valgus, minimally invasive surgery, review. in superior radiographic outcomes compared to the MIS Reverdin-Isham osteotomy. Sufficient correction of IMA cannot be achieved with the MIS Reverdin-Isham osteotomy.

To date, multiple different surgical techniques have been established for hallux valgus surgery, with each having its unique advantages and limitations. The open distal chevron osteotomy is widely accepted as a method for correcting mild to moderate hallux valgus deformities (1) with numerous studies presenting good radiological $(2,3)$ and clinical outcomes $(4,5)$. Scarring and decreased range of motion of the greater toe joint after open surgery (6) as well as increasing patient demands have led several minimally invasive (MIS) techniques to be described in recent years (710). The corrective power and its stability, as well as the clinical outcome of different MIS techniques are discussed controversially to date (11-13). Recently, two prospective randomized studies comparing the MIS and the open distal chevron osteotomy were published with comparable clinical and radiographic outcomes after short- and long-term followup $(14,15)$. Whereas most studies presented good clinical and radiological results $(9,14-16)$, the group of CrespoRomero found insufficient radiographic hallux valgus angle (HVA) correction (17). Nevertheless, in various systematic review studies of MIS hallux valgus correction a clear recommendation could not be made although early results were encouraging (18-22). The uncertainty of outcome following minimally invasive hallux surgery might be a consequence of analyzing different surgical techniques without methodological differentiation between these techniques. Thus, it might be beneficial to evaluate outcomes after MIS surgery with regard to the applied technique. 
Given the above-mentioned lack of evidence it was the aim of the study to compare the results of two different specific MIS techniques for hallux valgus correction. Since MIS distal chevron has been shown to provide comparable results to the open technique for correction of mild to moderate hallux valgus deformities $(14,15)$, we analyzed this technique in comparison to the Reverdin-Isham procedure, which is known as the technique that made MIS surgery popular (19). It was hypothesized that the two techniques would show significant differences with regard to radiological outcome (Hypothesis 1) and clinical outcome (Hypothesis 2).

\section{Patients and Methods}

The study was conducted in accordance with the ethical standards outlined in the 1964 World Medical Association Declaration of Helsinki and its later amendments following the Consolidated Standards of Reporting Trials (CONSORT) guidelines. The local ethics committee approved the present study (1062/2018). The study has been listed on ClinicalTrials.gov (identifier: NCT04288297). The review was designed according to the recommendations in the literature (23) for systematic reviews of the literature and metaanalysis (24).

Search strategy. In October 2019, a bibliographic search was conducted in the PubMed/Medline and EMBASE databases. The search terms used were "hallux valgus" and "Reverdin Isham" or "minimally invasive" or "percutaneous" or "distal osteotomy" or "oblique osteotomy". Exclusively articles in English or Spanish, without limitation of year of publication, assessing the described surgical method with a minimum follow-up of 6 months and presenting results in terms of clinical or radiological data were included. Primary selection was made after reading the title and the published abstracts. The selected articles were read and checked for eligibility by two authors independently (GK and ML). Our search strategy produced 33 studies for "hallux valgus" and "Reverdin Isham". In combination with "percutaneous" or "minimally invasive" 21 studies remained. After exclusion of articles published not in English or Spanish language, and of studies presenting data on patients treated not with distal Reverdin-Isham osteotomies 15 studies remained. Two selected abstracts found in Pubmed were not available as full papers $(25,26)$. Two other studies were identified in the reference list of another included study $(27,28)$. After doublechecking for duplicates, 15 studies were available for full paper review $(7,17,25,28-39)$ and all were reviewed. One study had to be excluded, because a proximal metatarsal osteotomy was performed in addition to the Reverdin osteotomy (39). Seven of these studies could not be used for statistical meta-analysis because the data set was incomplete (no defined follow-up time, missing radiological and/or clinical data). The selection process and reasons for exclusion are shown in the flow diagram in Figure 1. Overall standardized mean correction of specific radiographic angles was performed using a forest-plot analysis. For this analysis another study had to be excluded, because an additional metatarsal osteotomy had been performed in $27 \%$ of the study cohort (17). One study analyzed outcomes after unilateral and bilateral ReverdinIsham osteotomy separately (29). Therefore, these two groups were regarded as two original studies in our meta-analysis.
Table I. Quality assessment for Reverdin-Isham studies at latest followup, MIS chevron (present series) and a Level I MIS chevron study from the literature.

\begin{tabular}{lccc}
\hline Investigator & $\begin{array}{c}\text { Level of } \\
\text { evidence }\end{array}$ & MINORS & $\begin{array}{c}\text { CMS } \\
\text { score }\end{array}$ \\
\hline De Prado et al. (22) & 4 & na & 48 \\
Barragan Hervella et al. (38) & 4 & na & 17 \\
Bauer et al. (31) & 2 & $12 / 16$ & 62 \\
Bauer et al. (30) & 4 & $11 / 16$ & 52 \\
Gicquel et al. (28) & 4 & $8 / 16$ & 42 \\
Cervi et al. (37) & 4 & $6 / 16$ & 35 \\
Rodriguez Reyes et al. (35) & 4 & na & 36 \\
Biz et al. (32) & 4 & $12 / 24$ & 60 \\
Carvalho et al. (29) unilateral & 4 & $7 / 16$ & 28 \\
Carvalho et al. (29) bilateral & 4 & $7 / 16$ & 35 \\
DiGiorgio et al. (25) & 2 & $15 / 24$ & na \\
Crespo Romero et al. (17) & 2 & $9 / 16$ & 54 \\
Severyns et al. (34) & 4 & $7 / 16$ & 42 \\
Present series & 3 & $21 / 24$ & 70 \\
MIS Chevron (15) & 1 & $22 / 24$ & 85 \\
\hline
\end{tabular}

CMS: Coleman methodology score; MINORS: methodological index for non-randomized studies; na: not applicable.

The results after MIS Reverdin-Isham osteotomy presented in the published literature were compared with a prospective series of 57 feet in 49 patients with mild to moderate hallux valgus deformity treated with MIS distal chevron osteotomy performed at our department between October 2012 and November 2016. All patients were invited to participate and gave written informed consent prior to inclusion. Exclusion criteria were: 1) age $<18$ years, 2) previous surgical hallux valgus correction on the same foot, 3) tarsometatarsal joint instability of the first ray, defined as painful motion in this joint, 4) symptomatic osteoarthritis of the first metatarsophalangeal joint, 5) preoperative hallux valgus angle (HVA) of less than 20 degrees $(40,41), 6)$ an intermetatarsal angle (IMA) of less than 10 degrees (42) with regard to the definition of hallux valgus deformity or IMA surmounting 15 degrees to exclude patients with more severe deformities.

Outcome parameters. For all examined patients clinical outcome in terms of 1) range of motion (ROM) of the first metatarsophalangeal joint, categorized in three groups (group 1: $\mathrm{ROM}<30^{\circ}$; group 2: ROM $31^{\circ}-75^{\circ}$; group $3: \operatorname{ROM}>75^{\circ}$ ), 2 ) a pain score (visual analogue scale - VAS 0-10), 3) and the AOFAS (American Orthopaedic Foot \& Ankle Society) Forefoot Scale was assessed as it has been described previously $(14,15)$. Radiographic outcome was measured on weightbearing radiographs in digital manner using the Icoview software (syngo.share, ITH icoserve healthcare GmbH, Siemens, Innsbruck, Austria) in the form of a single researcher single measurement approach (MB). All the evaluated parameters were the following and have been previously described $(14,15)$ : lateralization of the sesamoids (4-fold, 7-fold), the hallux valgus angle (HVA), the intermetatarsal angle (IMA), the distal metatarsal articular angle (DMAA), the proximal to distal phalangeal articular angle (PDPAA), and the joint congruity angle (JC), shown by tangential lines running along the edges of the joint of the metatarsal head and the base of the phalangeal bone. Additionally, osteoarthritis was assessed in our 


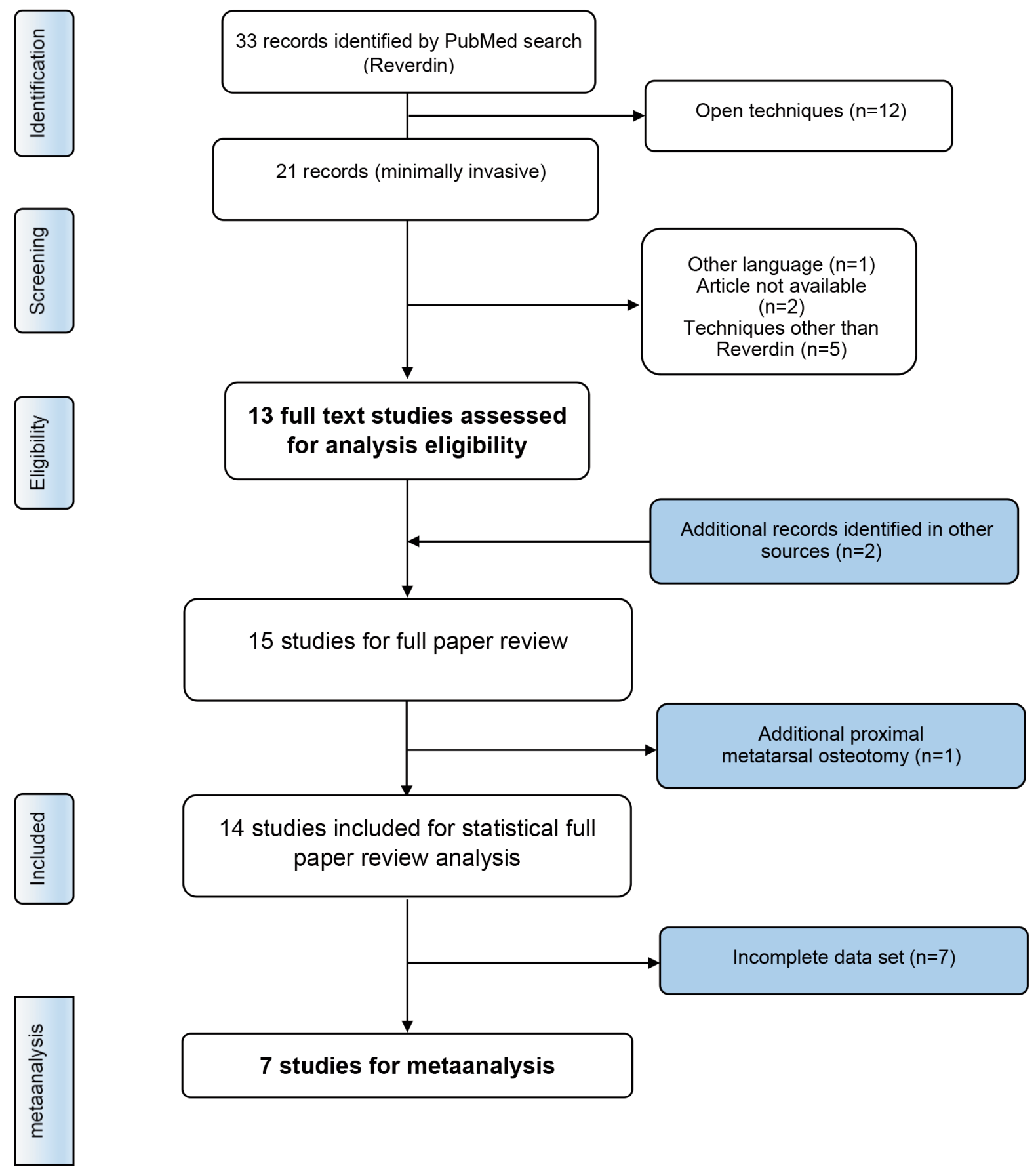

Figure 1. Flow diagram of studies included and excluded in the present analysis.

chevron cohort with the 4-fold Kellgren-Lawrence grading scale (43). Outcome was evaluated preoperatively, after six weeks, 12 weeks and nine months postoperatively and at final follow-up.

Surgical technique. All surgeries were performed by one single consultant foot and ankle surgeon (GK). The surgical technique of this V-shaped osteotomy has already been described in the literature
(14). MIS distal chevron osteotomy was performed percutaneously through a dorsomedial incision of 3-5 $\mathrm{mm}$. With a sliding osteotomy of the metatarsal head the correction the IMA is intended. In 45 feet a phalangeal Akin osteotomy was added. The MIS Reverdin-Isham osteotomy technique has been well described in the literature as well (32). The concept of this osteotomy is a medial based closing wedge osteotomy of the metatarsal head without addressing the IMA. 
in vivo $35: 2187-2196(2021)$

Table II. Demographic data from Reverdin-Isham studies at latest follow-up, MIS chevron (present series) and a Level I MIS chevron study from the literature.

\begin{tabular}{|c|c|c|c|c|c|c|c|}
\hline Investigator & Year & Patients & Feet & $\begin{array}{l}\text { Age at time of } \\
\text { surgery (ys) }\end{array}$ & Right/Left & $\begin{array}{c}\text { Male } \\
\text { /Female }\end{array}$ & $\begin{array}{c}\text { Average } \\
\text { follow-up (mo) }\end{array}$ \\
\hline De Prado et al. (22) & 2003 & 64 & 64 & $\mathrm{nr}$ & $\mathrm{nr}$ & $\mathrm{nr}$ & $24-37$ \\
\hline Barragan Hervella et al. (38) & 2008 & 29 & 29 & $\mathrm{nr}$ & $\mathrm{nr}$ & $\mathrm{nr}$ & 6 \\
\hline Bauer et al. (31) & 2009 & 168 & 189 & 55 & $97 / 92$ & $4 / 164$ & 13 \\
\hline Bauer et al. (30) & 2010 & 82 & 104 & 57 & $55 / 49$ & $6 / 76$ & 24 \\
\hline Gicquel et al. (28) & 2013 & 18 & 33 & 12.5 & $\mathrm{nr}$ & $0 / 18$ & 31.4 \\
\hline Cervi et al. (37) & 2014 & 213 & 213 & 55 & $\mathrm{nr}$ & $29 / 184$ & $5-29$ \\
\hline Rodriguez Reyes et al. (35) & 2014 & 11 & 20 & $\mathrm{nr}$ & $\mathrm{nr}$ & $\mathrm{nr}$ & $6-12$ \\
\hline Biz et al. (32) & 2016 & 80 & 80 & 51 & $43 / 37$ & $5 / 75$ & 48 \\
\hline Carvalho et al. (29) unilateral & 2016 & 29 & 29 & 61.5 & $\mathrm{nr}$ & $0 / 29$ & 24 \\
\hline Carvalho et al. (29) bilateral & 2016 & 32 & 64 & 58.7 & $32 / 32$ & $4 / 60$ & 28 \\
\hline DiGiorgio et al. (25) & 2016 & 19 & 19 & $\mathrm{nr}$ & $\mathrm{nr}$ & $\mathrm{nr}$ & 23.3 \\
\hline Crespo Romero et al. (17) & 2017 & 108 & 132 & 56.1 & $66 / 66$ & $7 / 125$ & 57.3 \\
\hline Severyns et al. (34) & 2018 & 48 & 57 & 51.5 & $\mathrm{nr}$ & $5 / 43$ & 60.1 \\
\hline Present series & 2020 & 49 & 57 & 53.2 & $25 / 32$ & $5 / 52$ & 58.9 \\
\hline MIS Chevron (15) & 2020 & 36 & 39 & 54 & $23 / 19$ & $6 / 33$ & 67.1 \\
\hline
\end{tabular}

ys: Years; mo: months; nr: not reported.

Table III. Radiological results from included Reverdin-Isham studies at latest follow-up, MIS chevron (present series) and a Level I MIS chevron study from the literature.

\begin{tabular}{|c|c|c|c|c|c|c|c|}
\hline \multirow[t]{2}{*}{ Investigator } & \multicolumn{2}{|c|}{ HVA } & \multicolumn{2}{|c|}{ IMA } & \multicolumn{2}{|c|}{ DMAA } & \multirow{2}{*}{$\begin{array}{l}\text { Follow-up } \\
\text { time (months) }\end{array}$} \\
\hline & Preop & Postop & Preop & Postop & Preop & Postop & \\
\hline De Prado et al. (22) & $\mathrm{nr}$ & $\mathrm{nr}$ & 14.5 & 9.5 & $\mathrm{nr}$ & $\mathrm{nr}$ & $24-37$ \\
\hline Barragan Hervella et al. (38) & $\mathrm{nr}$ & $\mathrm{nr}$ & $\mathrm{nr}$ & $\mathrm{nr}$ & $\mathrm{nr}$ & $\mathrm{nr}$ & 6 \\
\hline Bauer et al. (31) & 28 & 14 & 13 & 10 & 15 & 8 & 13 \\
\hline Bauer et al. (30) & 30 & 15 & 14 & 11 & 15 & 7 & 24 \\
\hline Gicquel et al. (28) & 28.1 & 19.5 & 13.6 & 12.7 & 16.0 & 9.0 & 31.4 \\
\hline Cervi et al. (37) & $\mathrm{nr}$ & $\mathrm{nr}$ & $\mathrm{nr}$ & $\mathrm{nr}$ & $\mathrm{nr}$ & $\mathrm{nr}$ & $5-29$ \\
\hline Rodriguez Reyes et al. (35) & 24.8 & 15.5 & 9.7 & 9.5 & $\mathrm{nr}$ & $\mathrm{nr}$ & $6-12$ \\
\hline Biz et al. (32) & 26.4 & 13.9 & 12.9 & 9 & 10.1 & 5.4 & 48 \\
\hline Carvalho et al. (29) unilateral & 32.5 & 19.5 & 14.3 & 13.6 & 13.5 & 6 & 24 \\
\hline Carvalho et al. (29) bilateral & 34.1 & 19.2 & 13.4 & 12.4 & 16.1 & 8.1 & 28 \\
\hline DiGiorgio et al. (25) & 30.2 & 13.1 & 14.1 & 8.9 & $\mathrm{nr}$ & $\mathrm{nr}$ & 23.3 \\
\hline Crespo Romero et al. (17) & 34.3 & 22.5 & 13.1 & 10.7 & 18.5 & 23.6 & 57.3 \\
\hline Severyns et al. (34) & 29.3 & 15.4 & 13.5 & 12 & 14.1 & 7.7 & 60.1 \\
\hline Present series & 29.9 & 8.5 & 13.3 & 6.1 & 21.0 & 6.7 & 58.9 \\
\hline MIS Chevron (15) & 26.4 & 12.0 & 14.2 & 6.9 & 24.5 & 9.8 & 67.1 \\
\hline
\end{tabular}

HVA: Hallux valgus angle; IMA: intermetatarsal angle; DMAA: distal metatarsal articular angle.

Statistical analysis. Statistical analysis was performed using the IBM SPSS Statistics for Windows, Version 24.0 (IBM Corp., Armonk, NY) and MedCalc Statistical Software version 18.2.1 (MedCalc Software bvba, Ostend, Belgium). Descriptive statistical analyses included the calculation of means (range) and medians (IQR) for continuous measures, and numbers ( $n$, with percentages) for categorical variables. Three meta-analyses were performed to integrate the quantitative findings with regard to IMA, HVA and DMAA deformity angles of the selected studies. For the meta- analyses, Hedges g statistics was used as a formulation for the standardized mean differences between baseline and follow-up measurement of the deformity angles. The standardized mean difference Hedges $g$ is the difference between the two means divided by the pooled standard deviation, with a correction for small sample bias. The forest plots show, for each deformity angle, the results of the different studies included in the meta-analysis, with $95 \%$ confidence intervals for the standardized mean differences. The diamonds display the aggregated differences $(95 \%$ 
Table IV. Clinical results from Reverdin-Isham studies at latest follow-up, MIS chevron (present series) and a Level I MIS chevron study from the literature.

\begin{tabular}{|c|c|c|c|c|c|c|}
\hline \multirow[t]{2}{*}{ Investigator } & \multicolumn{2}{|c|}{ VAS } & \multicolumn{2}{|c|}{ AOFAS } & \multicolumn{2}{|c|}{ ROM } \\
\hline & Preop & Postop & Preop & Postop & Preop & Postop \\
\hline De Prado et al. (22) & $\mathrm{nr}$ & $\mathrm{nr}$ & $\mathrm{nr}$ & $\mathrm{nr}$ & $\mathrm{nr}$ & $\mathrm{nr}$ \\
\hline Barragan Hervella et al. (38) & $\mathrm{nr}$ & $\mathrm{nr}$ & 60.4 & 96.6 & $\mathrm{nr}$ & $\mathrm{nr}$ \\
\hline Bauer et al. (31) & $\mathrm{nr}$ & $\mathrm{nr}$ & 52 & 93 & 90 & 75 \\
\hline Bauer et al. (30) & $\mathrm{nr}$ & $\mathrm{nr}$ & 49 & 87.5 & 95 & 80 \\
\hline Gicquel et al. (28) & $\mathrm{nr}$ & $\mathrm{nr}$ & $\mathrm{nr}$ & 80.7 & $\mathrm{nr}$ & $\mathrm{nr}$ \\
\hline Cervi et al. (37) & $\mathrm{nr}$ & $\mathrm{nr}$ & 45 & 90 & $\mathrm{nr}$ & $\mathrm{nr}$ \\
\hline Rodriguez Reyes et al. (35) & $\mathrm{nr}$ & $\mathrm{nr}$ & 60.5 & 95.7 & $\mathrm{nr}$ & $\mathrm{nr}$ \\
\hline Biz et al. (32) & $\mathrm{nr}$ & 8.3 & 54.1 & 87.2 & $\mathrm{nr}$ & $\mathrm{nr}$ \\
\hline Carvalho et al. (29) unilateral & $\mathrm{nr}$ & $\mathrm{nr}$ & $\mathrm{nr}$ & 82.9 & $\mathrm{nr}$ & $\mathrm{nr}$ \\
\hline Carvalho et al. (29) bilateral & $\mathrm{nr}$ & $\mathrm{nr}$ & $\mathrm{nr}$ & 88.6 & $\mathrm{nr}$ & $\mathrm{nr}$ \\
\hline DiGiorgio et al. (25) & $\mathrm{nr}$ & $\mathrm{nr}$ & 40.5 & 90.3 & $\mathrm{nr}$ & $\mathrm{nr}$ \\
\hline Crespo Romero et al. (17) & 6.3 & 1.9 & 50.6 & 85.9 & $\mathrm{nr}$ & $\mathrm{nr}$ \\
\hline Severyns et al. (34) & $\mathrm{nr}$ & $\mathrm{nr}$ & 55.9 & 89.2 & 98 & 71.5 \\
\hline Present series & 6 & 0.5 & 64 & 95.3 & 90 & 96 \\
\hline MIS chevron(15) & 5 & 0 & 65 & 95 & 85 & 92 \\
\hline
\end{tabular}

VAS: Visual analogue scale; AOFAS: American Orthopaedic Foot And Ankle Society forefoot scale; nr: not reported.

confidence intervals), both, for the fixed and the random effects calculation method. Results of our own patients' series were added to the forest plots. A statistically significant difference $(p<0.05)$ is indicated if the results of the own series does not overlap with the aggregated results of the meta-analysis displayed by the diamonds in the forest plots.

\section{Results}

In a first approach the methodological and thus scientific quality of the included papers was investigated using the previously described Methodological Index for NonRandomized Studies (MINORS) (44), the Coleman Methodology Scale (22) and the level of evidence. Concise details of the included studies concerning the methodological limitations are given in Table I. The reporting criteria are in reference to the critical appraisal tool proposed previously (45). Quality assessment revealed low scientific quality of the analyzed Reverdin-Isham studies. In a second step the studies were assessed with regard to the reported clinical and radiological outcome.

Table II presents patient demographics for the analyzed Reverdin-Isham studies. Concise clinical and radiological data from each included study are presented in Tables III and IV. A significant number of the analyzed Reverdin-Isham studies showed radiographic recurrence for IMA and HVA (Table III). However, scientific quality of the published Reverdin-Isham studies was low.

Clinical and radiographic results after MIS distal chevron osteotomy are presented in Tables V and VI. Mean followup was 58.9 (range=39.0-85.4) months. The MIS chevron showed good correction of all relevant angles of the hallux valgus deformity to all points of survey without major loss of correction until follow-up. Clinical outcome in terms of VAS and AOFAS also showed major improvement to all points of assessment. ROM stayed consistent from pre- to postoperative. Two feet showed radiographic recurrence with a IMA above ten degrees and five feet with a HVA above $20^{\circ}$ at latest follow-up. However, only two of these feet showed a reduced AOFAS score as well.

Radiographic outcomes of the MIS chevron and of the meta-analysis of the MIS Reverdin-Isham osteotomy are shown in Figures 2, 3, and 4 using the forest plot analysis. Outcomes of IMA, HVA, and DMAA are presented separately. Radiographic outcomes were significantly better with the MIS chevron than with the Reverdin-Isham osteotomy $(p<0.05)$.

\section{Discussion}

Our results showed superior radiographic outcomes with regard to IMA, HVA, and DMAA after MIS distal chevron osteotomy compared to MIS Reverdin-Isham osteotomy. However, clinical outcomes were comparable with both techniques.

With the distal MIS chevron osteotomy, we were able to correct IMA, HVA, and DMAA in patients with mild to moderate hallux valgus. The degree of correction found in our study is well in line with the published literature on MIS distal chevron osteotomy $(15,16,27,46)$. PDPAA, joint congruity angle, and sesamoid position showed good correction until final follow-up at a mean of 58.9 (range=39.0-85.4) months as well. 
Table V. Clinical data of the present MIS Chevron cohort.

\begin{tabular}{lccc}
\hline & Mean & SD & Range \\
\hline $\begin{array}{l}\text { Osteoarthritis preoperative } \\
\text { (grade 0-4) }\end{array}$ & 0.8 & 0.7 & $0-2$ \\
Osteoarthritis 6 weeks & 0.6 & 0.7 & $0-2$ \\
Osteoarthritis 12 weeks & 0.6 & 0.6 & $0-2$ \\
Osteoarthritis 9 months & 0.8 & 0.7 & $0-3$ \\
Osteoarthritis FU & 0.9 & 0.8 & $0-3$ \\
VAS preoperative (0-10) & 5.6 & 1.3 & $3-8$ \\
VAS 6 weeks & 1.4 & 1.6 & $0-7$ \\
VAS 12 weeks & 0.8 & 1.3 & $0-7$ \\
VAS 9 months & 0.9 & 1.5 & $0-7$ \\
VAS FU & 0.5 & 0.9 & $0-4$ \\
AOFAS preoperative (points) & 64.4 & 11.3 & $37-93$ \\
AOFAS 6 weeks & 84.2 & 10.2 & $55-95$ \\
AOFAS 12 weeks & 90.2 & 7.2 & $72-100$ \\
AOFAS 9 months & 92.2 & 7.7 & $70-100$ \\
AOFAS FU & 95.3 & 6.1 & $75-100$ \\
\hline & Mean & SD & Number \\
& & & of feet \\
& & & in group \\
& & & $0 / 1 / 2$ \\
\hline ROM preoperative & 1.5 & 0.6 & $2 / 26 / 29$ \\
(group 0-1-2) & 1.1 & 0.4 & $1 / 49 / 6$ \\
ROM 6 weeks & 1.4 & 0.5 & $1 / 33 / 22$ \\
ROM 9 months & 0.5 & $1 / 24 / 31$ \\
ROM FU & 0.5 & $0 / 23 / 34$ \\
\hline
\end{tabular}

ROM: Range of motion; VAS: visual analogue scale; AOFAS: American Orthopaedic Foot And Ankle Society forefoot scale; SD: standard deviation; FU: follow-up.

The concept of the MIS distal chevron osteotomy is a sliding maneuver of the first metatarsal head, whereas for the Reverdin-Isham it is a closing wedge technique. In accordance to this, the correction of the deformity can be expected to a greater extent using a MIS distal chevron osteotomy. In our study, a better correction of IMA could be found with the MIS chevron osteotomy than with the MIS Reverdin-Isham technique. Mean postoperative IMA amounted to $11.6^{\circ}$ with the Reverdin-Isham method, while with the MIS chevron technique IMA was corrected to $6.1^{\circ}$ on the mean. Three of the analyzed Reverdin-Isham studies reported a total correction of $3^{\circ}$ for IMA (30-32), while the other three studies even less than $3^{\circ}(31,36,42)$. Insufficient radiographic correction following the MIS Reverdin-Isham osteotomy has been already described (47). Nevertheless, this procedure was meant to be a valid procedure for correcting a hallux valgus deformity and is still a frequently used minimally invasive technique for hallux valgus correction (47).

Preoperative radiological deformity in terms of IMA, HVA, DMAA, joint congruence and sesamoid position as
Table VI. Radiological data of the present MIS Chevron cohort.

\begin{tabular}{|c|c|c|c|}
\hline & Mean & SD & Range \\
\hline IMA preoperative (degrees) & 13.3 & 2.6 & $8.7-21.1$ \\
\hline IMA 6 weeks & 6.2 & 3.1 & $0.7-19.2$ \\
\hline IMA 12 weeks & 6.2 & 2.6 & $1.0-12.6$ \\
\hline IMA 9 months & 5.9 & 2.8 & $0.7-17.2$ \\
\hline IMA FU & 6.1 & 2.1 & $1.2-10.7$ \\
\hline HVA preoperative (degrees) & 29.9 & 9.4 & $11.6-62.3$ \\
\hline HVA 6 weeks & 8.9 & 7.1 & $16.4-24.0$ \\
\hline HVA 12 weeks & 8.1 & 5.6 & $10.8-23.1$ \\
\hline HVA 9 months & 7.7 & 6.3 & $9.5-22.9$ \\
\hline HVA FU & 8.4 & 7.6 & $11.9-29.8$ \\
\hline DMAA preoperative (degrees) & 20.9 & 9.7 & $7.5-53.2$ \\
\hline DMAA 6 weeks & 8.7 & 7.0 & $0.2-2.9$ \\
\hline DMAA 12 weeks & 7.6 & 6.8 & $11.0-29.2$ \\
\hline DMAA 9 months & 5.5 & 4.9 & $4-22.8$ \\
\hline DMAA FU & 6.8 & 5.0 & $0-21.1$ \\
\hline PDPAA preoperative (degrees) & 8.4 & 4.8 & $0.4-19.9$ \\
\hline PDPAA 6 weeks & 4.3 & 3.4 & $0-15$ \\
\hline PDPAA 12 weeks & 4.3 & 3.4 & $0-15.5$ \\
\hline PDPAA 9 months & 4.1 & 3.3 & $0.2-16.1$ \\
\hline PDPAA FU & 4.2 & 3.2 & $0.1-13.9$ \\
\hline Joint congruity preoperative (degrees) & 8.9 & 9.5 & $0-52.7$ \\
\hline Joint congruity 6 weeks & 3.7 & 5.3 & $0-34$ \\
\hline Joint congruity 12 weeks & 4.3 & 4.6 & $0.1-21$ \\
\hline Joint congruity 9 months & 4.2 & 4.8 & $0-28.4$ \\
\hline Joint congruity FU & 3.8 & 3.9 & $0-15.8$ \\
\hline Sesamoids preoperative (7-part) & 4.0 & 1.3 & $2-7$ \\
\hline Sesamoids 6 weeks & 1.5 & 0.7 & $0-4$ \\
\hline Sesamoids 12 weeks & 1.6 & 0.8 & $0-4$ \\
\hline Sesamoids 9 months & 1.8 & 0.9 & $0-6$ \\
\hline Sesamoids FU & 1.9 & 0.9 & $0-6$ \\
\hline Sesamoids preoperative (4-part) & 2.4 & 0.9 & $1-4$ \\
\hline Sesamoids 6 weeks & 0.8 & 0.7 & $0-3$ \\
\hline Sesamoids 12 weeks & 0.9 & 0.8 & $0-4$ \\
\hline Sesamoids 9 months & 1.2 & 1.0 & $0-4$ \\
\hline Sesamoids FU & 1.3 & 1.0 & $0-4$ \\
\hline
\end{tabular}

IMA: Intermetatarsal angle; HVA: hallux valgus angle; DMAA: distal metatarsal articular angle; PDPAA: proximal to distal phalangeal articular angle; SD: standard deviation; FU: follow-up.

well as insufficient hallux valgus correction has been linked to hallux valgus recurrence after long-term follow-up (48). Consequently, we feel that for sufficient hallux valgus deformity correction these specific pathological radiographic angles should be corrected to normal. With regard to the definition of a hallux valgus recurrence with a HVA of more than $15^{\circ}$ and an IMA of more than $10^{\circ}$ (48), radiographic recurrence is likely with the Reverdin-Isham method. In our meta-analysis mean postoperative IMA amounted to $11.6^{\circ}$ with the Reverdin-Isham method, what does equate to radiographic recurrence. Interestingly, clinical outcome in terms of AOFAS forefoot score was generally good in the Reverdin-Isham studies as well. This might be a consequence of the variable and short follow-up times of the 
Bauer et al. (30)

Bauer et al. (31)

Gicquel et al. (28)

Biz et al. (32)

Carvalho et al. - unilateral (29)

Carvalho et al. - bilateral (29)

Severyns et al. (34)

Total (fixed effects)

Total (random effects)

present MIS Chevron Series

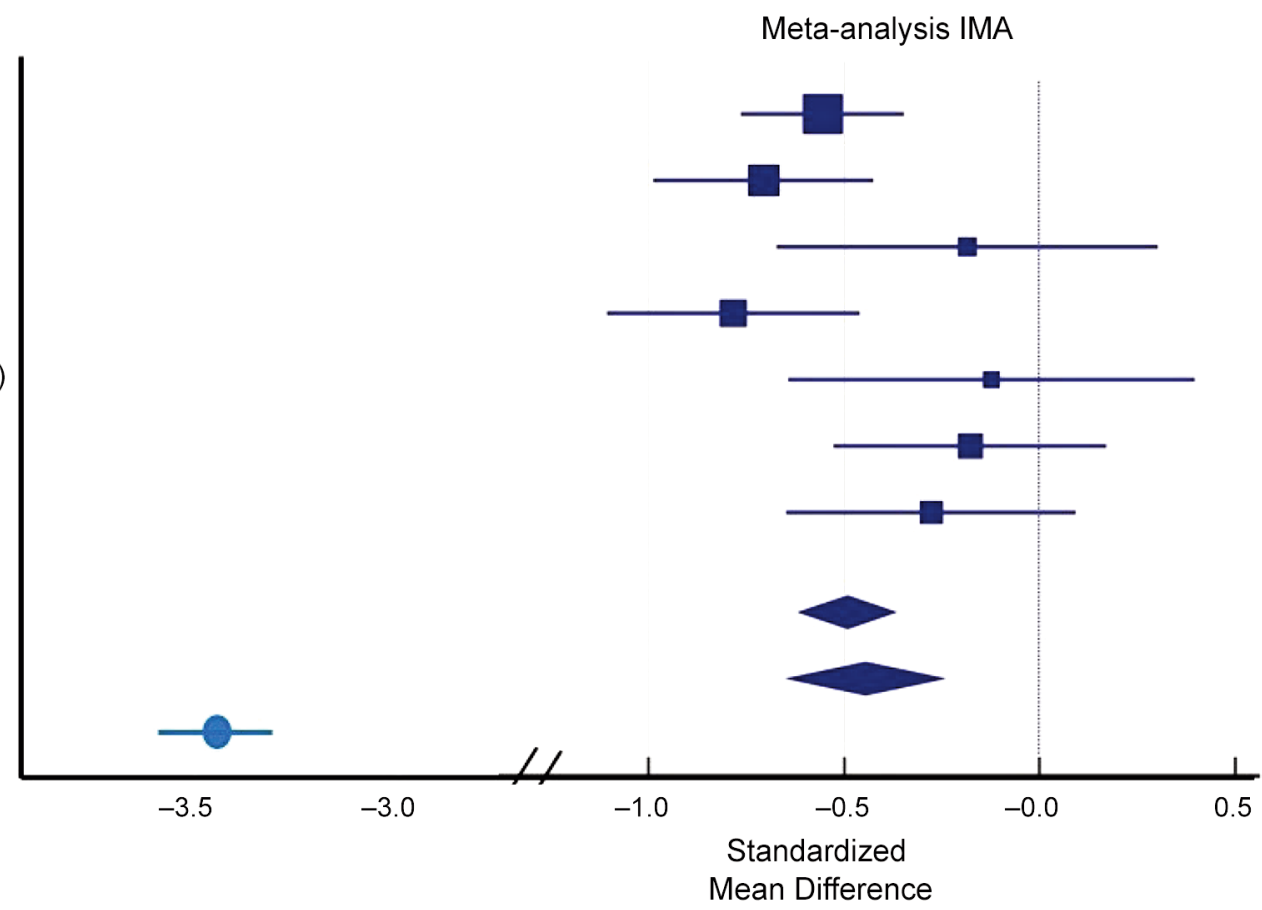

Figure 2. Forest plot meta-analysis showing the intermetatarsal angle (IMA) results for the various Reverdin-Isham studies (squares) and the present MIS chevron series (circle) with 95\% CI. The overall standardized mean difference as well as random effects are shown as well (diamonds).

Bauer et al. (30)

Bauer et al. (31)

Gicquel et al. (28)

Biz et al. (32)

Carvalho et al. - unilateral (29)

Carvalho et al. - bilateral (29)

Severyns et al. (34)

Total (fixed effects)

Total (random effects)

present MIS Chevron Series

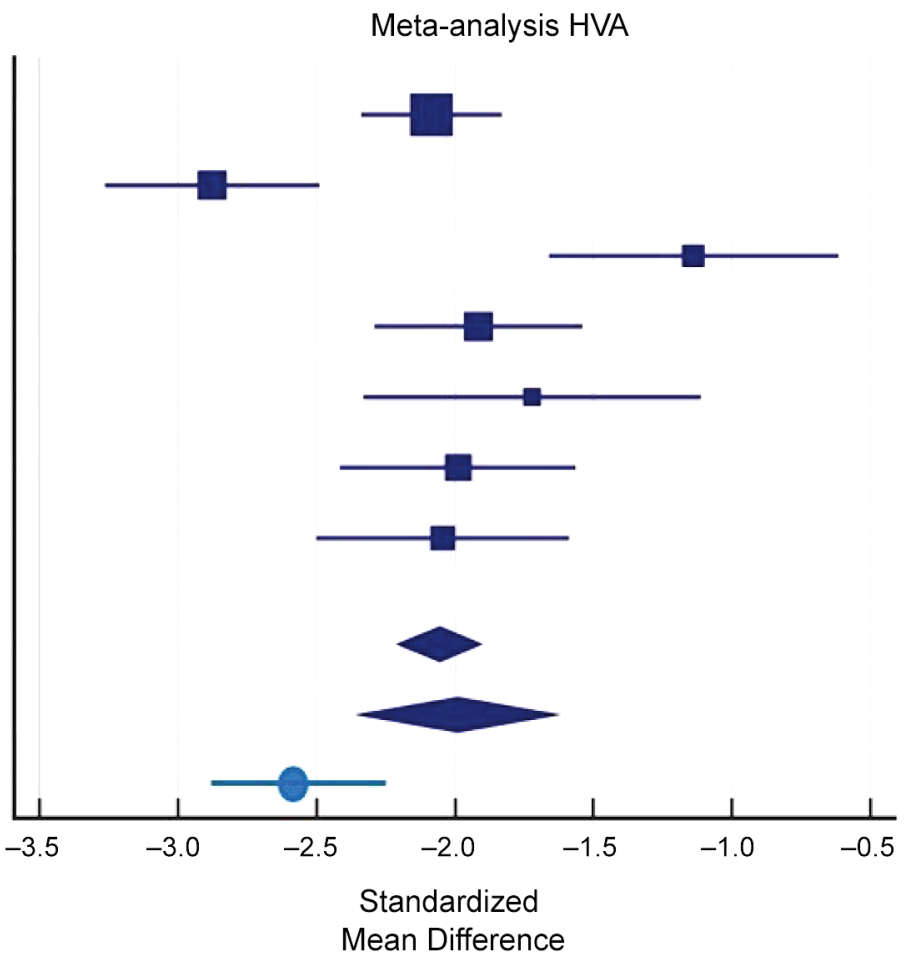

Figure 3. Forest plot meta-analysis showing the hallux valgus angle (HVA) results for the various Reverdin-Isham studies (squares) and the present MIS chevron series (circle) with 95\% CI. The overall standardized mean difference as well as random effects are shown as well (diamonds). 


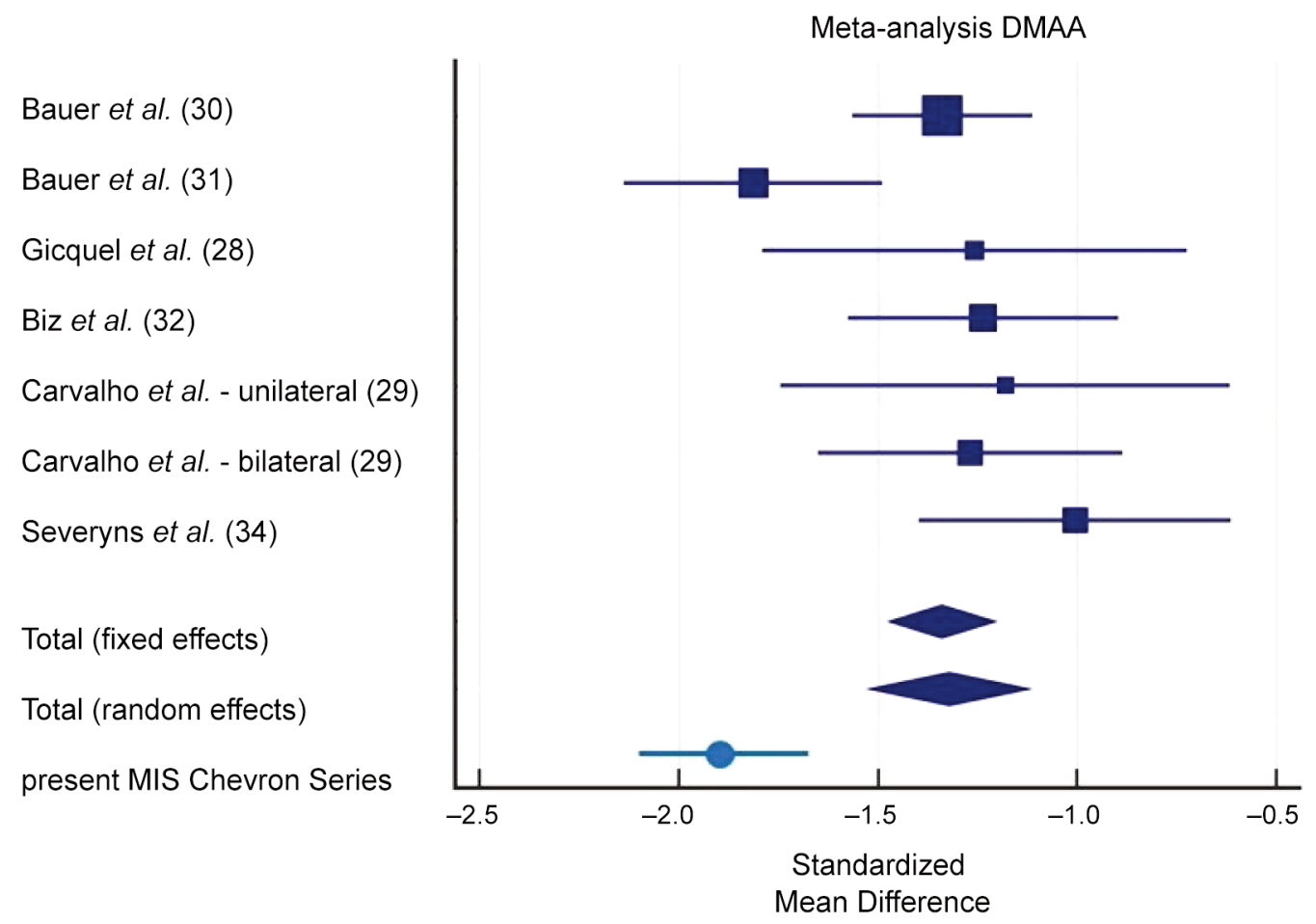

Figure 4. Forest plot meta-analysis showing the distal metatarsal articular angle (DMAA) results for the various Reverdin-Isham studies (squares) and the present MIS chevron series (circle) with 95\% CI. The overall standardized mean difference as well as random effects are shown as well (diamonds).

analyzed studies. At long-term follow-up this might result in clinical appearance of hallux valgus recurrence.

Improvement of clinical outcome in terms of AOFAS forefoot score and VAS, comparable to that in the published literature $(15,30,38)$ was found in our cohort of MIS distal chevron osteotomies as well as in the Reverdin-Isham studies (28-32, 34). We did not observe loss of ROM of the first metatarsophalangeal joint after MIS chevron osteotomy. ROM was reported only in 3 of our included Reverdin-Isham studies and showed a slight reduction of ROM. However, this finding had no impact on clinical outcome in terms of AOFAS forefoot score $(30,31,34)$.

Our meta-analysis of published literature on MIS Reverdin-Isham osteotomy revealed a high probability of random effects. We ascribe this finding to the poor scientific quality of some Reverdin-Isham publications. Full text assessment revealed a large variety of methodological descriptions, number of included feet and follow-up time. Additionally, demographic data were partially incomplete and the statistical description unprecise. Consequently, only half of the included studies could be used for meta-analysis.

A major limitation of our study stems from the study design, namely a comparison of the results of a cohort treated by the authors with one distinct surgical method and the results of another cohort treated with a different surgical technique. The poor scientific quality of the studies on MIS Reverdin-Isham osteotomy found in the literature is another limitation. The single-observer single-measurement analysis of the present MIS chevron series and the design as a singlecenter study is another limitation. The most positive aspect remains the size of the patient cohort treated with the MIS distal chevron osteotomy at our department with no dropouts until follow-up.

\section{Conclusion}

MIS distal chevron osteotomy in mild to moderate hallux valgus deformity correction results in superior radiographic outcomes compared to the MIS Reverdin-Isham osteotomy. Sufficient correction of IMA cannot be achieved with the MIS Reverdin-Isham osteotomy.

\section{Conflicts of Interest}

The Authors declare that there are no conflicts of interest.

\section{Authors' Contributions}

G. Kaufmann: Study protocol, study design, literature research, data analysis, editing and writing of the article. D. Weiskopf: Literature 
research, data analysis, editing, writing and proofreading of the article M. Liebensteiner: Co-editing, proofreading of the article. H. Ulmer: Data analysis and proofreading of the article. M. Braito: Literature research, supervised the study results and proofread the article. F. Endstrasser: Co-editing, proofreading of the article. M. Wagner: Coediting, proofreading of the article. M. Ban: Literature research, Coediting, proofreading of the article. D. Dammerer: Study protocol, study design, literature research, data analysis, editing and writing of the article. All Authors made pertinent contributions to the article, and proofread and approved the final article before submission.

\section{Acknowledgements}

The Authors would like to thank Mary Heaney Margreiter for providing language correction.

\section{References}

1 Trnka HJ, Zembsch A, Easley ME, Salzer M, Ritschl P and Myerson MS: The chevron osteotomy for correction of hallux valgus. Comparison of findings after two and five years of follow-up. J Bone Joint Surg Am 82(10): 1373-1378, 2000. PMID: 11057464.

2 Oh IS, Choi SW, Kim MK, Lee SY and Lee JS: Clinical and radiological results after modified distal metatarsal osteotomy for hallux valgus. Foot Ankle Int 29(5): 473-477, 2008. PMID: 18510898. DOI: 10.3113/FAI-2008-0473

3 Choi WJ, Yoon HK, Yoon HS, Kim BS and Lee JW: Comparison of the proximal chevron and Ludloff osteotomies for the correction of hallux valgus. Foot Ankle Int 30(12): 11541160, 2009. PMID: 20003873. DOI: 10.3113/FAI.2009.1154

4 Thordarson D, Ebramzadeh E, Moorthy M, Lee J and Rudicel S: Correlation of hallux valgus surgical outcome with AOFAS forefoot score and radiological parameters. Foot Ankle Int 26(2): 122-127, 2005. PMID: 15737253. DOI: 10.1177/107110070 502600202

5 Park $\mathrm{CH}$, Jang JH, Lee $\mathrm{SH}$ and Lee WC: A comparison of proximal and distal chevron osteotomy for the correction of moderate hallux valgus deformity. Bone Joint J 95-B(5): 649-656, 2013. PMID: 23632675. DOI: 10.1302/0301-620X.95B5.30181

6 Vopat BG, Lareau CR, Johnson J, Reinert SE and DiGiovanni CW: Comparative study of scarf and extended chevron osteotomies for correction of hallux valgus. Foot Ankle Spec 6(6): 409-416, 2013. PMID: 24154993. DOI: 10.1177/ 1938640013508431

7 Brogan K, Voller T, Gee C, Borbely T and Palmer S: Thirdgeneration minimally invasive correction of hallux valgus: technique and early outcomes. Int Orthop 38(10): 2115-2121, 2014. PMID: 25128969. DOI: 10.1007/s00264-014-2500-1

8 Jowett CRJ and Bedi HS: Preliminary results and learning curve of the minimally invasive Chevron Akin operation for hallux valgus. J Foot Ankle Surg 56(3): 445-452, 2017. PMID: 28237566. DOI: $10.1053 /$ j.jfas.2017.01.002

9 Lee M, Walsh J, Smith MM, Ling J, Wines A and Lam P: Hallux valgus correction comparing percutaneous Chevron/Akin (PECA) and open Scarf/Akin osteotomies. Foot Ankle Int 38(8): 838-846, 2017. PMID: 28476096. DOI: 10.1177/1071100717704941

10 Redfern D and Perera AM: Minimally invasive osteotomies. Foot Ankle Clin 19(2): 181-189, 2014. PMID: 24878408. DOI: $10.1016 /$ j.fcl.2014.02.002
11 Huang PJ, Lin YC, Fu YC, Yang YH and Cheng YM: Radiographic evaluation of minimally invasive distal metatarsal osteotomy for hallux valgus. Foot Ankle Int 32(5): S503-S507, 2011. PMID: 21733458. DOI: 10.3113/FAI.2011.0503

12 Giannini S, Cavallo M, Faldini C, Luciani D and Vannini F: The SERI distal metatarsal osteotomy and Scarf osteotomy provide similar correction of hallux valgus. Clin Orthop Relat Res 471(7): 2305-2311, 2013. PMID: 23494184. DOI: $10.1007 / \mathrm{s} 11999-013-2912-\mathrm{z}$

13 Holme TJ, Sivaloganathan SS, Patel B and Kunasingam K: Third-generation minimally invasive Chevron Akin osteotomy for hallux valgus. Foot Ankle Int 41(1): 50-56, 2020. PMID: 31522534. DOI: $10.1177 / 1071100719874360$

14 Kaufmann G, Dammerer D, Heyenbrock F, Braito M, Moertlbauer L and Liebensteiner M: Minimally invasive versus open chevron osteotomy for hallux valgus correction: a randomized controlled trial. Int Orthop 43(2): 343-350, 2019. PMID: 29869014. DOI: 10.1007/s00264-018-4006-8

15 Kaufmann G, Mörtlbauer L, Hofer-Picout P, Dammerer D, Ban M and Liebensteiner M: Five-year follow-up of minimally invasive distal metatarsal chevron osteotomy in comparison with the open technique: a randomized controlled trial. J Bone Joint Surg Am 102(10): 873-879, 2020. PMID: 32149929. DOI: 10.2106/ JBJS.19.00981

16 Brogan K, Lindisfarne E, Akehurst H, Farook U, Shrier W and Palmer S: Minimally invasive and open distal Chevron osteotomy for mild to moderate hallux valgus. Foot Ankle Int 37(11): 11971204, 2016. PMID: 27381179. DOI: 10.1177/1071100716656440

17 Crespo Romero E, Peñuela Candel R, Gómez Gómez S, Arias Arias A, Arcas Ordoño A, Gálvez González J and Crespo Romero R: Percutaneous forefoot surgery for treatment of hallux valgus deformity: an intermediate prospective study. Musculoskelet Surg 101(2): 167-172, 2017. PMID: 28168637. DOI: $10.1007 / \mathrm{s} 12306-017-0464-1$

18 Maffulli N, Longo UG, Marinozzi A and Denaro V: Hallux valgus: effectiveness and safety of minimally invasive surgery. A systematic review. Br Med Bull 97: 149-167, 2011. PMID: 20710024. DOI: $10.1093 / \mathrm{bmb} / \mathrm{ldq} 027$

19 Malagelada F, Sahirad C, Dalmau-Pastor M, Vega J, Bhumbra R, Manzanares-Céspedes MC and Laffenêtre O: Minimally invasive surgery for hallux valgus: a systematic review of current surgical techniques. Int Orthop 43(3): 625-637, 2019. PMID: 30218181. DOI: 10.1007/s00264-018-4138-x

20 Trnka HJ, Krenn S and Schuh R: Minimally invasive hallux valgus surgery: a critical review of the evidence. Int Orthop 37(9): 17311735, 2013. PMID: 23989262. DOI: 10.1007/s00264-013-2077-0

21 Singh MS, Khurana A, Kapoor D, Katekar S, Kumar A and Vishwakarma G: Minimally invasive $v s$. open distal metatarsal osteotomy for hallux valgus - A systematic review and metaanalysis. J Clin Orthop Trauma 11(3): 348-356, 2020. PMID: 32405192. DOI: $10.1016 /$ j.jcot.2020.04.016

22 Bia A, Guerra-Pinto F, Pereira BS, Corte-Real N and Oliva XM: Percutaneous osteotomies in hallux valgus: A systematic review. J Foot Ankle Surg 57(1): 123-130, 2018. PMID: 28870735. DOI: 10.1053/j.jfas.2017.06.027

23 Wright RW, Brand RA, Dunn W and Spindler KP: How to write a systematic review. Clin Orthop Relat Res 455: 23-29, 2007. PMID: 17279036. DOI: 10.1097/BLO.0b013e31802c9098

24 Moher D, Liberati A, Tetzlaff J, Altman DG and PRISMA Group: Preferred reporting items for systematic reviews and meta- 
analyses: the PRISMA statement. PLoS Med 6(7): e1000097, 2009. PMID: 19621072. DOI: 10.1371/journal.pmed.1000097

25 Di Giorgio L, Sodano L, Touloupakis G, De Meo D and Marcellini L: Reverdin-Isham osteotomy versus Endolog system for correction of moderate hallux valgus deformity: a Randomized Controlled Trial. Clin Ter 167(6): e150-e154, 2016. PMID: 28051828. DOI: 10.7417/CT.2016.1960

26 Weinberger BH, Fulp JM, Falstrom P, Anavian RR, Gore AI and Bazak I: Retrospective evaluation of percutaneous bunionectomies and distal osteotomies without internal fixation. Clin Podiatr Med Surg 8(1): 111-136, 1991. PMID: 2015523.

27 Giannini S, Faldini C, Nanni M, Di Martino A, Luciani D and Vannini F: A minimally invasive technique for surgical treatment of hallux valgus: simple, effective, rapid, inexpensive (SERI). Int Orthop 37(9): 1805-1813, 2013. PMID: 23820757. DOI: 10.1007/s00264-013-1980-8

28 Gicquel T, Fraisse B, Marleix S, Chapuis M and Violas P: Percutaneous hallux valgus surgery in children: short-term outcomes of 33 cases. Orthop Traumatol Surg Res 99(4): 433 439, 2013. PMID: 23623317. DOI: 10.1016/j.otsr.2013.02.003

29 Carvalho P, Viana G, Flora M, Emanuel P and Diniz P. Percutaneous hallux valgus treatment: Unilaterally or bilaterally. Foot Ankle Surg 22(4): 248-253, 2016. PMID: 27810023. DOI: 10.1016/j.fas.2015.11.002

30 Bauer T, Biau D, Lortat-Jacob A and Hardy P: Percutaneous hallux valgus correction using the Reverdin-Isham osteotomy. Orthop Traumatol Surg Res 96(4): 407-416, 2010. PMID: 20488776. DOI: $10.1016 /$ j.otsr.2010.01.007

31 Bauer T, de Lavigne C, Biau D, De Prado M, Isham S and Laffenétre O: Percutaneous hallux valgus surgery: a prospective multicenter study of 189 cases. Orthop Clin North Am 40(4): $505-$ 14, ix, 2009. PMID: 19773056. DOI: 10.1016/j.ocl.2009.05.002

32 Biz C, Fosser M, Dalmau-Pastor M, Corradin M, Rodà MG, Aldegheri $\mathrm{R}$ and Ruggieri $\mathrm{P}$ : Functional and radiographic outcomes of hallux valgus correction by mini-invasive surgery with Reverdin-Isham and Akin percutaneous osteotomies: a longitudinal prospective study with a 48-month follow-up. J Orthop Surg Res 11(1): 157, 2016. PMID: 27919259. DOI: 10.1186/s13018-016-0491-x

33 Acar B, Kose O, Unal M, Turan A, Kati YA and Guler F: Comparison of magnesium versus titanium screw fixation for biplane chevron medial malleolar osteotomy in the treatment of osteochondral lesions of the talus. Eur J Orthop Surg Traumatol 30(1): 163-173, 2020. PMID: 31375999. DOI: 10.1007/s00590019-02524-1

34 Severyns M, Carret P, Brunier-Agot L, Debandt M, Odri GA and Rouvillain JL: Reverdin-Isham procedure for mild or moderate hallux valgus: clinical and radiographic outcomes. Musculoskelet Surg 103(2): 161-166, 2019. PMID: 30151785. DOI: 10.1007/ s12306-018-0563-7

35 Rodríguez-Reyes G, López-Gavito E, Pérez-Sanpablo AI, Galván Duque-Gastélum C, Alvarez-Camacho M, Mendoza-Cruz F, Parra-Téllez P, Vázquez-Escamilla J and Quiñones-Urióstegui I: [Dynamic plantar pressure distribution after percutaneous hallux valgus correction using the Reverdin-Isham osteotomy]. Rev Invest Clin 66(Suppl 1): S79-S84, 2014. PMID: 25264801.

36 Pichierri P, Sicchiero P, Fioruzzi A and Maniscalco P: Percutaneous hallux valgus surgery: strengths and weakness in our clinical experience. Acta Biomed 85(Suppl 2): 121-125, 2014. PMID: 25409732.
37 Cervi S, Fioruzzi A, Bisogno L and Fioruzzi C: Percutaneous surgery of allux valgus: risks and limitation in our experience. Acta Biomed 85(Suppl 2): 107-112, 2014. PMID: 25409729.

38 Barragán-Hervella RG, Morales-Flores F, Arratia-Ríos M, BuzoGarcidueñas AY, Nesme-Avila W and García-Villaseñor A: Clinical results of hallux valgus minimally surgery. Acta Ortop Mex 22(3): 150-156, 2008. PMID: 18826077.

39 Díaz Fernández R: Treatment of moderate and severe hallux valgus by performing percutaneous double osteotomy of the first metatarsal bone. Rev Esp Cir Ortop Traumatol 59(1): 52-58, 2015. PMID: 25284596. DOI: 10.1016/j.recot.2014.07.002

40 HARDY RH and CLAPHAM JC: Observations on hallux valgus; based on a controlled series. J Bone Joint Surg Br 33-B(3): 376-391, 1951. PMID: 14861244. DOI: 10.1302/0301620X.33B3.376

41 VENNING P: Sources of error in the production and measurement of standard radiographs of the foot. Br J Radiol 24(277): 18-26, 1951. PMID: 14801487. DOI: 10.1259/00071285-24-277-18

42 Wülker N: Hallux valgus. Orthopade 26(7): 654-664, 1997. PMID: 28246805. DOI: 10.1007/s001320050137

43 Kohn MD, Sassoon AA and Fernando ND: Classifications in Brief: Kellgren-Lawrence Classification of Osteoarthritis. Clin Orthop Relat Res 474(8): 1886-1893, 2016. PMID: 26872913. DOI: $10.1007 / \mathrm{s} 11999-016-4732-4$

44 Slim K, Nini E, Forestier D, Kwiatkowski F, Panis Y and Chipponi J: Methodological index for non-randomized studies (minors): development and validation of a new instrument. ANZ J Surg 73(9): 712-716, 2003. PMID: 12956787. DOI: 10.1046/ j.1445-2197.2003.02748.x

45 Rangel SJ, Kelsey J, Henry MC and Moss RL: Critical analysis of clinical research reporting in pediatric surgery: justifying the need for a new standard. J Pediatr Surg 38(12): 1739-1743, 2003. PMID: 14666456. DOI: 10.1016/j.jpedsurg.2003.08.033

46 Faour-Martín O, Martín-Ferrero MA, Valverde García JA, VegaCastrillo A and de la Red-Gallego MA: Long-term results of the retrocapital metatarsal percutaneous osteotomy for hallux valgus. Int Orthop 37(9): 1799-1803, 2013. PMID: 23722318. DOI: 10.1007/s00264-013-1934-1

47 Crespo Romero E, Arcas Ordoño A, Peñuela Candel R, Gómez Gómez S, Arias Arias A, Gálvez González J and Crespo Romero $\mathrm{R}$ : Percutaneous hallux valgus surgery without distal metatarsal articular angle correction. Foot Ankle Spec 10(6): 502-508, 2017. PMID: 28068797. DOI: $10.1177 / 1938640016685147$

48 Pentikainen I, Ojala R, Ohtonen P, Piippo J and Leppilahti J: Preoperative radiological factors correlated to long-term recurrence of hallux valgus following distal chevron osteotomy. Foot Ankle Int 35(12): 1262-1267, 2014. PMID: 25192724. DOI: $10.1177 / 1071100714548703$ 